\title{
A review of recent progress in sensing of gas concentration by impedance change
}

\author{
Jonathan M. Rheaume • Albert P. Pisano
}

Received: 16 August 2010 /Revised: 16 November 2010 /Accepted: 12 December 2010 /Published online: 13 January 2011

(C) The Author(s) 2011. This article is published with open access at SpringerLink.com

\begin{abstract}
The intent of this paper is to establish the state of the art of impedance-based gas sensors. This sensor type holds promise for accurate detection of gaseous species at single parts per million and below. Impedance-based sensors do not require reference air to function, but do require calibration. Progress in the development of impedancemetric sensors for the detection of $\mathrm{NO}_{\mathrm{x}}, \mathrm{H}_{2} \mathrm{O}$, hydrocarbons, and $\mathrm{CO}$ is reviewed. Sensing electrodes typically consist of a noble metal or a metal oxide. YSZ is the preferred electrolyte material. Counter electrodes of Pt were common in asymmetric cells. These sensors typically operate at $500-700{ }^{\circ} \mathrm{C}$ and are interrogated at $10 \mathrm{~Hz}$ or less. Selectivity of these sensors remains a challenge especially in lean environments. Stability is an infrequently discussed yet important concern. Equivalent circuit analysis has shed light on various detection mechanisms. The impedance changes due to analyte gases are exhibited in parameters that represent the low frequency behavior of the electrochemical system. Although the search for a detailed mechanism continues, the change in impedance due to a specific gas is generally attributed to transport processes such as adsorption and charge transfer.
\end{abstract}

Keywords Impedancemetric gas sensor Impedance sensing - Electrochemical impedance spectroscopy (EIS) . Yttria-stabilized zirconia (YSZ)
Abbreviations
$C_{i} \quad$ capacitor
EIS electrochemical impedance spectroscopy

J. M. Rheaume $(\varangle) \cdot$ A. P. Pisano

University of California,

Berkeley, CA, USA

e-mail: jrheaume@alum.mit.edu
FG Fractal Gerischer element

$\mathrm{NO}_{\mathrm{x}}$ nitrogen oxides

ppm parts per million

OBD onboard diagnostics

PSZ partially stabilized zirconia

Q constant phase element

$\mathrm{R}_{\mathrm{i}} \quad$ resistor

SE sensing electrode

vpm volume parts per million

W Warburg element

YS Zyttria-stabilized zirconia

$\Delta \Theta \quad$ phase angle shift

$\Delta \mathrm{Z}$ change in modulus

\section{Introduction}

Sensors that detect gaseous species by potentiometric, mixed potential, or amperometric signals have conventionally been developed for automobile exhaust gas detection. A new variety of sensors that operate on the basis of an impedance change hold promise for accurate gas detection on the single parts per million (ppm) level even in $\mathrm{O}_{2}$ concentrations as high as $18.9 \%$ [1]. The simple, single cell design does not require an electrode for reference air however, selectivity, complicated supporting electronics, and long-term stability remain challenges [2], as discussed below.

Impedance-based sensors have a similar design as mixed potential type sensors. Instead of measuring the voltage, a sinusoidal voltage is applied and the resulting current is measured [3]. Impedance is then calculated as the ratio of voltage to current in the frequency domain. By using small amplitude sine wave perturbation, linearity in electrochemical systems can be assumed, allowing frequency analysis 
of a transfer function such as impedance. Analysis of impedance allows characterization of grain boundary resistance, mass transport rates, and chemical reaction rates [4]. Impedance analysis has also been further refined for the quantification of chemical species.

For almost two decades, the concept of sensing species by monitoring impedance has been known. Impedance sensors for gas detection are derived from original work on liquids. An early application of the impedance sensing technique involved monitoring blood glucose levels using a vascular prosthesis [5]. Gutiérrez et al. [6] investigated tin oxide $\left(\mathrm{SnO}_{2}\right)$ and noticed changes in the impedance spectra dependent on the surrounding gas atmosphere, whether it be humidified air, dry air, or blends of air and CO. They used a Voigt equivalent circuit to model their system. They stopped short of correlating changes in the impedance spectra to changes in species concentration.

The "theta" sensor concept pioneered by Weppner's group proposed using the ellipsoidal " $\theta$ " shape of a currentvoltage plot for detection of $\mathrm{CO}_{2}[7,8]$. They applied alternating perturbation signals to an electrochemical cell consisting of a fast solid electrolyte and various electrodes. Changes in partial pressure of analyte gas caused the shape of the plot to alter. Although impedance was not explicitly calculated, this analysis method was very similar to impedance spectroscopy. Phase angle was related to partial pressure [7]. An approximately linear relationship existed between phase angle and species in the window of $0-100 \mathrm{vpm}$. Curvature in this relationship could be seen over a larger window of partial pressure. The authors claimed several advantages of this type of sensor over potentiometric sensors: no reference electrode, better selectivity, more accurate detection, and improved response time [8]. Such "dynamic measurement" sensors were faster because thermoodynamic equilibria were not necessary [9].

Oelgeklaus and Baltruschat [10] proposed a hydrocarbon sensor with Pt electrodes and a sulfuric acid electrolyte. By continuously monitoring the impedance of their wet cell at a low frequency $(10 \mathrm{~Hz})$, they determined changes in capacitance of the electrode surface indicating the presence of hydrocarbon adsorbates. A follow-up paper by the same group reported a method to periodically strip the adsorbate from the surface to enable continuous monitoring of hydrocarbons. They also suggested a correction for $\mathrm{O}_{2}$ cross-sensitivity. They found a linear dependence of the sensor signal on concentration. The sensor struggled, however, to distinguish between hydrocarbon species [11].

Miura et al. [12] proposed a novel, yttria-stabilized zirconia (YSZ)-based sensor that relates gas composition to an impedance signal. In specific, the sensor detects total nitrogen oxides $\left(\mathrm{NO}_{\mathrm{x}}\right)$ concentration (both $\mathrm{NO}$ and $\mathrm{NO}_{2}$ ) down to $50 \mathrm{ppm}$ between $600{ }^{\circ} \mathrm{C}$ and $700{ }^{\circ} \mathrm{C}$ using a complex impedance signal. Sensitivity was measured by the difference in the magnitude of the impedance signal (modulus) measured at $0.1 \mathrm{~Hz}$ in air and in analyte gas. The change in modulus, $\Delta Z$, was approximately linear with $\mathrm{NO}_{\mathrm{x}}$ concentration from 50 to $400 \mathrm{ppm}$. Sensing behavior was attributed to changes of resistance at the interface between the YSZ electrolyte and the oxide electrode; in specific, gas adsorption and electrochemical reactions affected this resistance. Although the sensing mechanism of impedance-based sensors was not perfectly understood [2], it was evident that physicochemical processes impacted the impedance spectrum in the low frequency range.

In the following, the operating principles of impedancemetric sensors are discussed. An overview of recent literature on impedance-based detection of various gaseous species follows. Sensor materials, equivalent circuit models, and proposed sensing mechanisms are presented.

\section{Principle of operation}

The presence of various gases reversibly alters the impedance of some electrochemical systems at low frequencies $(f<100 \mathrm{~Hz})$ in a repeatable fashion that can be correlated to concentration. This principle underlies impedance-based gas sensors. Generally these sensors have a solid state electrolyte consisting of YSZ. Reference to external air is not necessary however, the sensor must be calibrated in order to correlate the signal to known gas concentrations.

Figure 1 depicts the operation of a symmetric, single cell, impedance-type sensor with a zirconia-based electrolyte. In this example case, $\mathrm{NO}_{\mathrm{x}}$ is the analyte species. First, gases diffuse to the electrode surfaces, where they adsorb, dissociate, and diffuse along the surface to the electrodeelectrolyte interface, followed by charge transfer (redox) reactions. Then ion transport through the electrolyte occurs with charge transfer across grain boundaries. At various frequencies, some of the processes may contribute to the impedance response, depending on the physical characteristics of the electrochemical cell and analyte species.

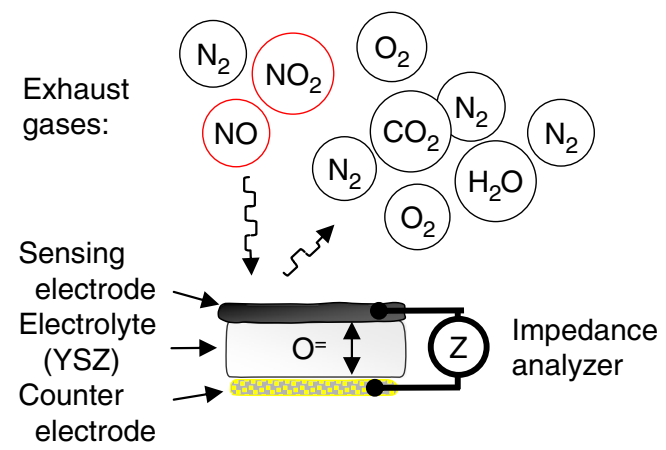

Fig. 1 Impedance-based $\mathrm{NO}_{\mathrm{x}}$ sensor operation 
The rate-limiting processes that occur at particular frequencies appear in the impedance spectra. Figure 2 shows a typical Nyquist plot of data recorded from a $\mathrm{NO}_{\mathrm{x}}$ sensor with an YSZ electrolyte, an Au working electrode, and a Pt counter electrode at $650{ }^{\circ} \mathrm{C}$. The plot shows the results of two measurements made when the sensor was exposed to two different gases: (1) $10 \% \mathrm{O}_{2}$ in $\mathrm{N}_{2}$ and (2) $10 \% \mathrm{O}_{2}$ in $\mathrm{N}_{2}$ with $100 \mathrm{ppm}$ NO. A Nyquist plot shows the resistive and capacitive contributions of impedance, but it does not explicitly show frequencies, so the six decades of frequency are indicated. Two impedance arcs labeled "high frequency" and "low frequency" resulted with both gas mixtures. The high frequency arc (approximately $f>10^{4} \mathrm{~Hz}$ ) provides information on kinetically controlled phenomena. Regardless of the gas, the high frequency arc remains invariant at a given temperature. In contrast, the low frequency arc (approximately $f<10^{4} \mathrm{~Hz}$ ) varies in the presence of various gas species; it is sensitive to transport events [13].

The effect of $100 \mathrm{ppm}$ NO is to shift the low frequency arc inwards. Both the modulus, $|Z|$, and phase angle, $\Theta$, change as a result. The modulus represents the length of the vector from the origin to an impedance measurement at a specific frequency $(10 \mathrm{~Hz})$. The phase angle is the arctangent of the ratio of the capacitive contribution of the impedance to the resistive component at a specific frequency. In Fig. 2, the moduli at $10 \mathrm{~Hz}$ are depicted and the corresponding phase angles are labeled. Upon exposure to an analyte gas, the changes in modulus [12] and changes in phase angle [1] are linear over a specific range of gas concentration at a given frequency. $\mathrm{A} \mathrm{NO}_{\mathrm{x}}$ sensor needs only to interrogate one frequency typically in the low frequency range (typically $f<100 \mathrm{~Hz}$ ) [2]. The frequency is selected as a compromise between speed of response, which favors higher frequencies, and sensitivity, which favors lower frequencies.

For a sensor application, the shape of the low frequency impedance spectrum must change selectively in the pres-

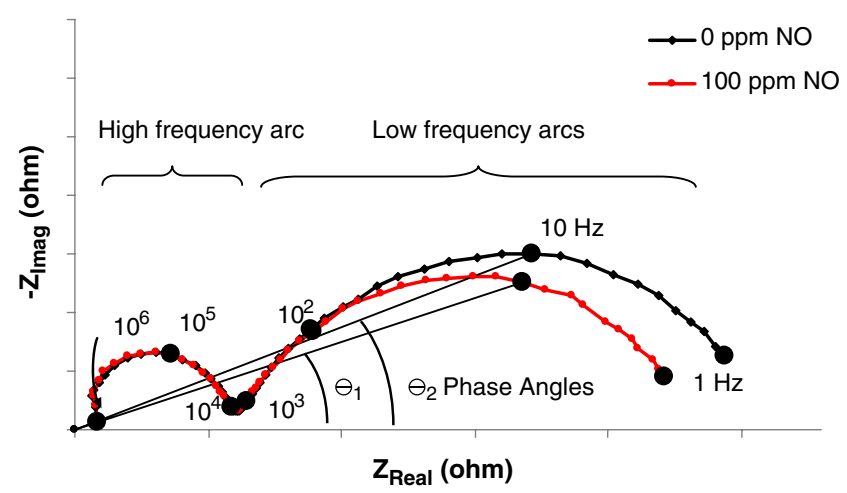

Fig. 2 NO causes inward shift of low frequency arc on Nyquist plot ence of a specific gas. If the change is not selective, then a compensation scheme must be possible.

\section{Review of literature on impedance-based gas sensing}

Impedance-based gas sensors are discussed in several books in the larger context of solid state sensors including amperometric and potentiometric varieties. Coauthors of the seminal paper [12] that related $\mathrm{NO}_{\mathrm{x}}$ concentration to changes in modulus discuss their impedance sensor work in books by Zhuiykov and/or Miura [2, 14, 15].

The application of impedance techniques to sensors with an electrolyte of YSZ is particularly relevant to gas sensing. In 1969, Bauerle [16] first applied impedance spectroscopy techniques to solid electrolytes of YSZ thereby setting the stage for the impedance detection mechanism. Since then, researchers have used the impedance change principle in sensors that detect $\mathrm{NO}_{\mathrm{x}}$, water vapor, hydrocarbons, and carbon monoxide. In the following sections, publications on impedance-based sensing are presented by the type of analyte gas and reviewed. A summary of impedance-type gas sensors appears in Table 1.

\section{Nitrogen oxides}

Impedance-type $\mathrm{NO}_{\mathrm{x}}$ detection is the least developed of all types of $\mathrm{NO}_{\mathrm{x}}$ sensors. It has shown promise to detect $\mathrm{NO}_{\mathrm{x}}$ at lower ppm than is possible using conventional sensors [3]. By " $\mathrm{NO}_{\mathrm{x}}$ ", one specifically refers to nitric oxide (NO) and nitrogen dioxide $\left(\mathrm{NO}_{2}\right)$, the two gaseous species that constitute virtually all $\mathrm{NO}_{\mathrm{x}}$ emissions from anthropogenic combustion processes [17]. For impedance-type $\mathrm{NO}_{\mathrm{x}}$ sensors, the response to $\mathrm{NO}$ and $\mathrm{NO}_{2}$ has been demonstrated to be comparable in magnitude and of the same sign (in contrast to mixed potential sensors) at specific temperatures, thereby facilitating the measurement of total $\mathrm{NO}_{\mathrm{x}}$ concentration [1, 12, 18-23]. Impedance-based gas sensors for gas detection may help diesel vehicles meet future $\mathrm{NO}_{\mathrm{x}}$ OBD requirements.

Ho et al. [24] noticed a change in the electrical properties of a thick film of $\mathrm{Nd}_{2} \mathrm{CuO}_{4-y}$ in the presence of $\mathrm{NO}_{x}$ gases. In specific, $\mathrm{NO}_{\mathrm{x}}$ gases caused changes in conductance that were related to species concentration.

Yoon et al. [25] noticed the effect of $\mathrm{NO}_{2}$ on impedance spectra in their experiments with potentiometric sensors. They remarked that the low frequency impedance associated with the electrode/electrolyte interface changed in the presence of $100 \mathrm{ppm} \mathrm{NO} \mathrm{N}_{2}$. They suggested that the oxygen groups from the $\mathrm{NO}_{2}$ decomposition caused a decrease in the overvoltage of the electrolyte/electrode interface. Other research groups built upon this finding by examining the impedance change over a wider range of partial pressures. 


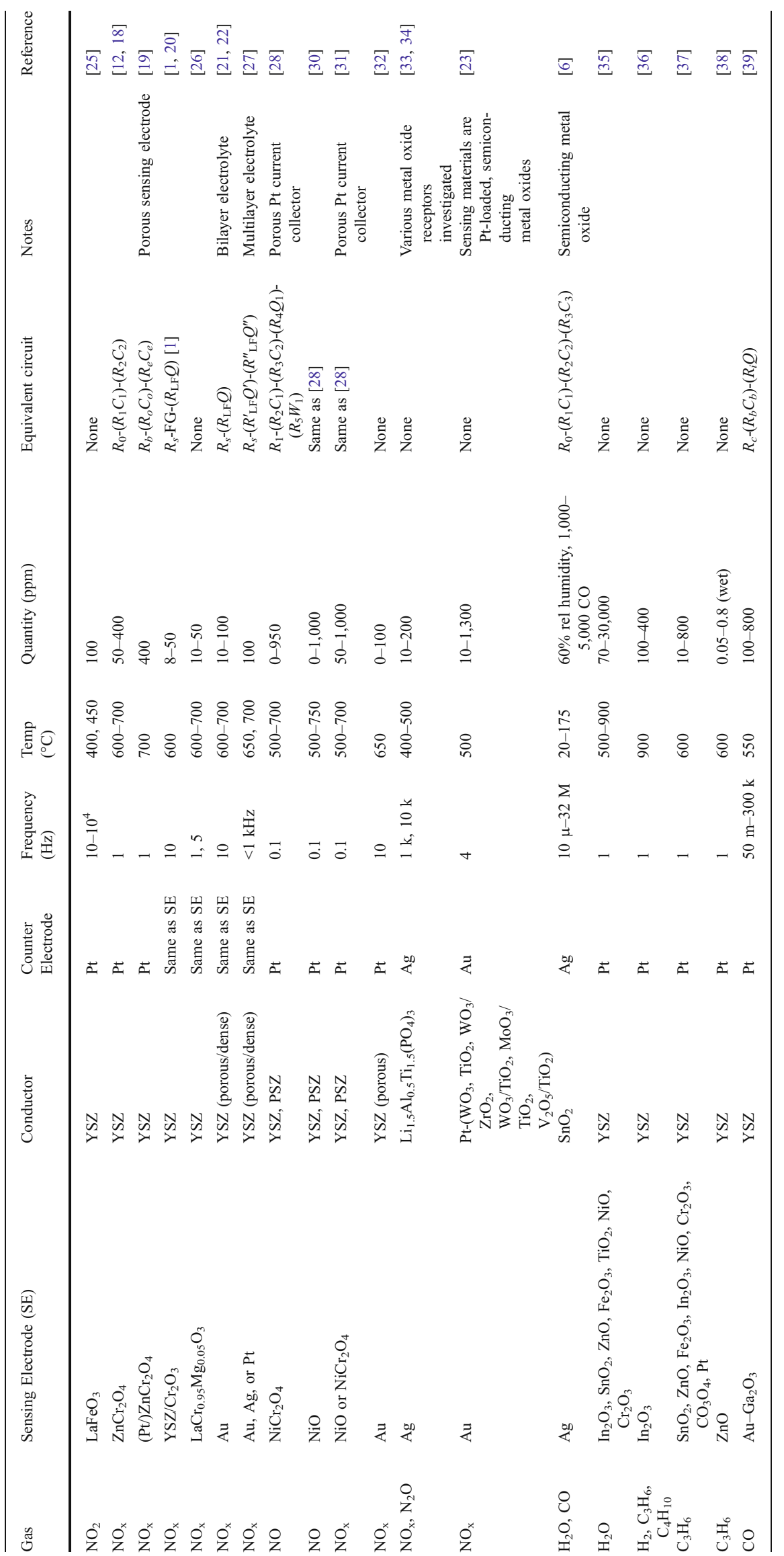


Miura et al. [12] originally proposed an impedancebased sensor with a $\mathrm{ZnCr}_{2} \mathrm{O}_{4}$ sensing electrode by calibrating a low frequency modulus shift with $\mathrm{NO}_{\mathrm{x}}$ concentration in a linear fashion, as described above. Subsequently, Miura et al. [18] further proposed an equivalent circuit model for the $\mathrm{NO}_{\mathrm{x}}$ sensor in a followup publication. Their circuit consists of a Voigt circuit with two Voigt elements: $R_{b}-\left(R_{o} C_{o}\right)-\left(R_{i} C_{i}\right)$. In their model, the lone resistor, $R_{b}$, represents YSZ bulk resistance; the first Voigt element $\left(R_{o} C_{o}\right)$ represents the resistance and capacitance of the bulk of the oxide electrode; finally, the second Voigt element $\left(R_{i} C_{i}\right)$ represents the resistance and capacitance of the interface between the YSZ and the oxide electrode where adsorption and reactions occur. Only the resistance of the interface changed in the presence of $\mathrm{NO}_{\mathrm{x}}$. It was suggested that this resistance or even the entire real component of impedance could be used to determine $\mathrm{NO}_{\mathrm{x}}$ concentration at low frequency however, the measurement should be taken by measuring complex impedance and by calculating the real component of resistance. In both these publications, Miura et al. called for further investigation in order to ascertain the sensing properties and detailed mechanism $[12,18]$.

Miura et al. then experimented with the thickness of $\mathrm{ZnCr}_{2} \mathrm{O}_{4}$ sensing electrodes in an impedance-based $\mathrm{NO}_{\mathrm{x}}$ sensor [19]. In some experiments, a platinum layer over the electrodes oxidized reducing gases that are known to evoke a cross-sensitive response $\left(\mathrm{CO}, \mathrm{H}_{2}, \mathrm{CH}_{4}\right.$, and $\left.\mathrm{C}_{3} \mathrm{H}_{8}\right)$ at $700{ }^{\circ} \mathrm{C}$. At high temperature, thick electrodes $(39 \mu \mathrm{m})$ provide a large catalytic area for non-equilibrium mixtures of $\mathrm{NO}$ and $\mathrm{NO}_{2}$ to equilibrate. An equilibrium $\mathrm{NO}_{\mathrm{x}}$ mixture at $700{ }^{\circ} \mathrm{C}$ consists of 95 vol. $\% \mathrm{NO}$ and 5 vol. $\% \mathrm{NO}_{2}$. Because $\mathrm{NO}_{2}$ is mostly reduced to $\mathrm{NO}$ during equilibration, the impedance-based sensor shows essentially the same response to $\mathrm{NO}$ as to $\mathrm{NO}_{2}$ at high temperature. They proposed that the sensing mechanism relies on the increased favorability of the electrochemical reaction involving oxygen in the presence of $\mathrm{NO}_{\mathrm{x}}$. A similar equivalent circuit was proposed as in previous work except that the Voigt element representing the low frequencies is associated with electrode reactions: $R_{b^{-}}\left(R_{o} C_{o}\right)-\left(R_{e} C_{e}\right)$.

Martin et al. applied a $\mathrm{NO}_{\mathrm{x}}$ sensing technique using impedance to a planar sensor with a YSZ electrolyte and identical metal-oxide composite electrodes consisting of $\mathrm{Cr}_{2} \mathrm{O}_{3}$ and $\mathrm{YSZ}\left(10: 90 \%\right.$ weight ratio) [20]. The $\mathrm{NO}_{\mathrm{x}}$ sensitivity was measured by the shift in phase angle at $10 \mathrm{~Hz}$. The shift was linear with concentration between 8 and $50 \mathrm{ppm}$. The response to both $\mathrm{NO}$ and $\mathrm{NO}_{2}$ was similar. They report different pathways for the $\mathrm{NO}$ and $\mathrm{O}_{2}$ reactions which supports the parallel path model. Since the $\mathrm{NO}_{\mathrm{x}}$ sensor is cross-sensitive to $\mathrm{O}_{2}$, a compensation method was proposed. They suggest that the simultaneous measurement of $\mathrm{NO}_{\mathrm{x}}$ and $\mathrm{O}_{2}$ can occur at different frequencies because the impedance response at $f>100 \mathrm{~Hz}$ was negligible for $\mathrm{NO}_{\mathrm{x}}$ but still significant for $\mathrm{O}_{2}$. The authors reported, however, that the response time of this sensor to $\mathrm{O}_{2}$ would need to decrease.

Subsequently, Martin et al. demonstrated that the change in phase angle was evident over a larger frequency range than the change in modulus, and thus the phase angle shift became their preferred metric [1]. They further developed an equivalent circuit model for their work on composite electrodes. Instead of the standard Voigt model, this group's model includes a fractal Gerischer element, which is used to model the diffusion of reacting gases. Their model consists of a series combination of a resistor, a fractal Gerischer (FG) element, and a Cole element: $R_{S}-F G-\left(R_{\mathrm{LF}} Q\right)$. The Cole element models the low frequency behavior. The most significant parameter changes due to $\mathrm{NO}_{\mathrm{x}}$ exposure occur in this subcircuit element. This element corresponds to physical processes that occur at the electrode surface and at the interface of the electrode and electrolyte. They further broke down the resistance of the Cole element into contributions from simultaneous reactions that occur at the triple phase boundary (interface) that involve $\mathrm{O}_{2}, \mathrm{NO}_{\mathrm{x}}$, and the ionic form of oxygen $\left(\mathrm{O}^{2-}\right)$ :

$R_{\mathrm{LF}}=\left[\frac{1}{R_{O 2}}+\frac{1}{R_{\mathrm{NOx}}}\right]^{-1}$

For an electrode to sense $\mathrm{NO}_{\mathrm{x}}$, the values of $\mathrm{RO}_{2}$ and $R_{\mathrm{NOx}}$ must be within two orders of magnitude of each other otherwise $\mathrm{NO}_{\mathrm{x}}$ detection is not possible. They confirmed this statement by adding a porous gold layer or a dense Pt plate to their electrodes; these actions both had the effect of increasing the electrode surface area for which $\mathrm{O}_{2}$ and $\mathrm{NO}_{\mathrm{x}}$ compete. The result was a decrease in $R_{2}$ to such an extent that the presence of $\mathrm{NO}_{\mathrm{x}}$ no longer could be detected. $R_{\mathrm{NOx}}$ was much greater than $R \mathrm{o}_{2}$; since $R_{\mathrm{NOx}}$ appears in the denominator, it did not contribute to the $R$ of the Cole element. Martin et al. also provided a justification for their use of change in phase angle, $\Delta \Theta$, instead of change in modulus, $|\mathrm{Z}|$, as the proxy for selectivity. The phase angle shift persists to higher frequency in the presence of $\mathrm{NO}_{\mathrm{x}}$ than does the modulus change. Increasing the frequency at which a sensor operates is desirable for a faster response. Since the sensor responds to both oxygen and $\mathrm{NO}_{\mathrm{x}}$ at $10 \mathrm{~Hz}$, but at $1 \mathrm{kHz}$ the sensor responds only to $\mathrm{O}_{2}$, compensation for $\mathrm{O}_{2}$ was carried out at $1 \mathrm{kHz}$ by measuring impedance. Phase angle varies linearly with $\mathrm{O}_{2}$ concentration over the examined range of $2-18.9 \%$ at both frequencies, so phase angles can be calibrated to determine $\mathrm{O}_{2}$ concentration at $1 \mathrm{kHz}$. Then the contribution of $\mathrm{O}_{2}$ can be subtracted from the impedance at $10 \mathrm{~Hz}$ in order to determine $\mathrm{NO}_{\mathrm{x}}$ concentration. Lastly, some signal drift was detected that may have been due to aging. A detailed study 
of the precise $\mathrm{NO}_{\mathrm{x}}$ sensing mechanism did not lie within the scope of this work.

Martin's coauthor, Murray, et al. investigated $\mathrm{NO}_{\mathrm{x}}$ sensors consisting of $\mathrm{LaCr}_{0.95} \mathrm{Mg}_{0.05} \mathrm{O}_{3}$ overlaid with $\mathrm{Ag}-\mathrm{Pd}$ on fully stabilized YSZ [26]. Phase angles were correlated to $\mathrm{NO}_{\mathrm{x}}$ concentration to serve as the measurement of sensitivity. An analysis of the effect of both $\mathrm{O}_{2}$ and temperature on sensitivity led them to conclude that monitoring these variables would be necessary for accurate sensing. The signal from sensors was found to drift over several days of operation due to material instability. In addition, long response times were required with these sensors. They posited charge transfer to be the ratelimiting step.

Yet another coauthor of Martin, Woo, investigated planar, YSZ-based $\mathrm{NO}_{\mathrm{x}}$ sensors with dense gold electrodes [21]. A porous layer of electrolyte was present between the electrodes and the dense electrolyte. This layer enabled enhanced $\mathrm{NO}_{\mathrm{x}}$ sensing, but the mechanism was not understood. A simplified equivalent circuit analysis was performed in which the low frequency arc that is sensitive to $\mathrm{NO}_{\mathrm{x}}$ was modeled by a resistor in series with a Cole element: $R_{s}-\left(R_{\mathrm{LF}} Q\right)$. $R_{\mathrm{LF}}$ represents the low frequency resistance that is affected by $\mathrm{O}_{2}$ and $\mathrm{NO}_{\mathrm{x}}$, and $R_{s}$ is a series resistor that serves as a simplification for the higher frequency behavior of the rest of the circuit. Adsorption was suggested as the rate-limiting mechanism responsible for sensing behavior, however, no definitive mechanistic conclusions were possible.

In a follow-up paper, Woo et al. [22] expatiated upon possible mechanisms for the $\mathrm{NO}_{\mathrm{x}}$ response of the symmetrical $\mathrm{Au} / \mathrm{YSZ}$ sensor. The resistor in the Cole element of the simplified equivalent circuit was proportional to the gas concentration according to a power law: $R_{\mathrm{LF}} \sim[\mathrm{gas}]^{\alpha}$. The determination of the exponent, $\alpha$, suggested adsorption as the sensing mechanism. In addition, the activation energies obtained from Arrhenius plots of $R_{1}$ tended to support adsorption. Competition for adsorption sites may have been the rate-limiting step. The authors called for further studies to explain the exact mechanism.

In a subsequent publication, Woo et al. [27] applied EIS techniques to NO sensors with $\mathrm{Au}, \mathrm{Pt}$, or $\mathrm{Ag}$ electrodes on a mixture of solid and porous YSZ electrolyte. Only $\mathrm{Au}$ showed sensing activity as long as the electrode was dense; porous gold was insensitive. The insensitivity of Pt makes it an appropriate counter electrode material. Sensors that detected NO featured larger impedance values than those that did not; this suggested that a dearth of electrochemical reaction sites may play a role in $\mathrm{NO}$ sensing. An equivalent circuit model was used to investigate the low frequency arc of NO impedance spectra. It was similar to a Voigt circuit but with the capacitors replaced by constant phase elements $(\mathrm{Q}): R_{s^{-}}\left(R_{\mathrm{LF}}^{\prime} Q^{\prime}\right)-\left(R_{\mathrm{LF}}^{\prime \prime} Q^{\prime \prime}\right)$. In this work once again, $R_{s}$ serves as an approximation for the total cell resistance at high frequencies $(>1 \mathrm{kHz})$. Two Cole elements were required to model one low frequency arc, implying that two physicochemical processes with similar time constants were taking place. Woo suggested that the rate-determining step for NO-sensing may depend on $\mathrm{O}_{2}$ reactions that take place away from the triple-phase boundary. Although the exact sensing mechanism was outside of the scope of this work and therefore not determined, adsorption and diffusion of $\mathrm{O}_{2}$ were offered as possible rate-limiting steps for the detection of NO.

Stranzenbach et al. [28] fabricated planar, impedancebased $\mathrm{NO}_{\mathrm{x}}$ sensors by sputtering sensing electrodes of the spinel $\mathrm{NiCr}_{2} \mathrm{O}_{4}$ on both fully stabilized YSZ and partially stabilized zirconia (PSZ) electrolyte. They measured sensitivity by the change in magnitude of the impedance, $\Delta \mathrm{Z}$, on the addition of a sample gas. From 200 to 1,000 ppm, $\Delta Z$ varied linearly with NO concentration at $0.1 \mathrm{~Hz}$. The impedance values and their associated magnitudes for the FSZ electrolyte were found to be much higher than those for PSZ. They analyzed the sensors for cross-sensitivity to various gases including $\mathrm{O}_{2}(0-20 \%), \mathrm{CH}_{4}(0-500 \mathrm{ppm})$, $\mathrm{CO}(0-100 \mathrm{ppm})$, and $\mathrm{CO}_{2}(0-500 \mathrm{ppm})$. They found that $\mathrm{CO}_{2}$ does not affect sensing performance for either electrolyte. In lean atmospheres, $\mathrm{CH}_{4}$ and $\mathrm{CO}$ are oxidized to $\mathrm{CO}_{2}$, so the sensor does not detect them either. In rich conditions, however, increases in both ohmic and capacitive resistance were observed and attributed to the reduction of the electrolyte. Typically electrolyte reduction is associated with a localized increase in electrons and a decrease in resistance [29]. No cross-sensitivity to $\mathrm{NO}_{2}$ was found because at high temperature $\left(T>600^{\circ} \mathrm{C}\right)$, the $\mathrm{NO}_{2}$ converts to $\mathrm{NO}$ at the electrodes due to thermodynamic equilibrium. They also identified an equivalent circuit model similar to a Voigt circuit, except in the last two elements, the capacitors are replaced with a constant phase element and a Warburg element, respectively: $R_{1^{-}}$ $\left(R_{2} C_{1}\right)-\left(R_{3} C_{2}\right)-\left(R_{4} Q_{1}\right)-\left(R_{5} W_{1}\right)$. They found that changes in NO concentration affect these last two elements of the equivalent circuit. The second to last element, a Cole element, consists of a resistor and constant phase element in parallel. It represents changes in the double layer between the electrode and electrolyte which may be due to the reaction of $\mathrm{NO}$ over the catalytic sensing electrode. The last element, a resistor in parallel with a Warburg impedance represent a diffusion process, but did not conclusively specify which species.

Stranzenbach and Saruhan [30] then examined impedancemetric $\mathrm{NO}_{\mathrm{x}}$ sensors with $\mathrm{NiO}$ as the sensing electrode on YSZ and PSZ electrolytes. This sensor showed excellent selectivity for $\mathrm{NO}$ in both reducing and oxidizing conditions with low cross-sensitivity to $\mathrm{O}_{2}$ and other combustible gases. 
In a subsequent paper, Stranzenbach and Saruhan [31] performed EIS on $\mathrm{NO}_{x}$ sensors with sputtered $\mathrm{NiO}$ or $\mathrm{NiCr}_{2} \mathrm{O}_{4}$ sensing electrodes on pre-aged electrolytes of fully stabilized YSZ and PSZ deposited by EBPVD. They used the same equivalent circuit as in their previous work [28]. The resistor of the Cole element represents the "reactionresistance" for adsorption, dissociation, and electrochemical reactions. It is an indicator of the oxygen sensitivity of the sensor. They also provided further discussion of the equivalent circuit and its relationship to the sensing mechanism. They postulated that the sensing mechanism was due to competitive molecular adsorption of $\mathrm{NO}$ and $\mathrm{O}_{2}$ for both sensing electrode types. In the case of the $\mathrm{NiCr}_{2} \mathrm{O}_{4}$ electrodes, NO dissociative adsorption controls the sensing behavior. They also posited that the impedancemetric $\mathrm{NO}_{\mathrm{x}}$ sensing behavior results from the charge transfer processes over the triple-phase boundary (TPB) and not from the anodic and cathodic reactions. The exact sensing mechanism and the factors that determine sensitivity were described as "open questions".

Rheaume et al. [32] used statistical "Design of Experiments" techniques to perform a two level, half fractional factorial experimental design $\left(2_{\mathrm{III}}{ }^{3-1}\right)$ on four single-cell impedancemetric $\mathrm{NO}_{\mathrm{x}}$ sensors $(\mathrm{Au} / \mathrm{YSZ} / \mathrm{Pt}$ ) to determine the effect of design features on sensitivity. Three design factors were systematically varied: working electrode area (number of sensing wires), electrolyte thickness, and the distance between sensing wires. Sensing ability was evaluated by performing electrochemical impedance spectroscopy and calculating the change in the phase angle at $10 \mathrm{~Hz}$ upon the introduction of $50 \mathrm{ppm} \mathrm{NO}$ or $\mathrm{NO}_{2}$ in $10 \%$ $\mathrm{O}_{2}$ with balance $\mathrm{N}_{2}$. ANOVA indicated that the most significant effect was electrolyte thickness for sensing NO. A linear relationship between phase angle difference and NO concentration existed, insensitive to total flow rate. $\mathrm{NO}_{\mathrm{x}}$ sensitivity was several orders of magnitude larger than for $\mathrm{O}_{2} . \mathrm{NO}_{2}$ evoked a larger response than $\mathrm{NO}$ at $650{ }^{\circ} \mathrm{C}$. Self-compensation by the simultaneous determination of both $\mathrm{O}_{2}$ and $\mathrm{NO}_{\mathrm{x}}$ concentrations was attempted by investigating the phase angle shifts at different frequencies $\left(1 \mathrm{kHz}\right.$ for $\mathrm{O}_{2}$ ). For this sensor chemistry, the phase angles did not exhibit dependence on gas concentration at frequencies of $1 \mathrm{kHz}$ and greater as reported by Martin et al. [1]. At $10^{5} \mathrm{~Hz}$, phase angles were linearly related to temperature, independent of gas species. As a result, a stable sensor may be calibrated for use as a thermometer, as long as the materials are stable (i.e., do not change due to aging). The authors did not specify the sensing mechanism, but mentioned that it is related to a transport process.

Y. Shimizu et al. investigated a fundamentally different electrochemical cell consisting of a non-zirconia electrolyte with two Ag electrodes and various metal oxide receptors contiguous to the electrolyte $[33,34]$. They used a lithium solid electrolyte, $\mathrm{Li}_{1.5} \mathrm{Al}_{0.5} \mathrm{Ti}_{1.5}\left(\mathrm{PO}_{4}\right)_{3}$, for their investigations of impedance-based $\mathrm{NO}_{\mathrm{x}}$ sensors [33]. This electrolyte operates at a lower temperature $\left(400-500{ }^{\circ} \mathrm{C}\right)$ than typical for zirconia electrolytes. They examined several different types of oxide receptors including numerous semiconductors and perovskites: $\mathrm{TiO}_{2}, \mathrm{SnO}_{2}, \mathrm{WO}_{3}, \mathrm{NiO}$, $\mathrm{Cr}_{2} \mathrm{O}_{3}, \mathrm{LaCrO}_{3}, \mathrm{LaMnO}_{3}, \mathrm{LaCoO}_{3}, \mathrm{LaFeO}_{3}$, and $\mathrm{LaNiO}_{3}$. The role of the receptors was to exchange electrons with the electrolyte, which affected the impedance of the cell. They noticed different responses for receptors consisting of $n$ type versus $p$-type semiconducting oxides. The sensors with $n$-type receptors showed good responses to $\mathrm{NO}_{\mathrm{x}}$ at $400{ }^{\circ} \mathrm{C}$. On the contrary, at $500{ }^{\circ} \mathrm{C}$ only the sensors with perovskite references $\mathrm{LaCrO}_{3}$ and $\mathrm{LaMnO}_{3}$ showed sensitivity to $\mathrm{NO}_{\mathrm{x}}$, Sensors were interrogated over a frequency range of $50 \mathrm{~Hz}$ to $5 \mathrm{MHz}$; for most sensors, they investigated the response $\Delta \mathrm{Z}$ at $1 \mathrm{kHz}$ or at $10 \mathrm{kHz}$, which is two to three orders of magnitude higher than other research. In specific, they were interested in the change of resistance and capacitance at a specific frequency due to the exposure of $\mathrm{NO}_{\mathrm{x}}$. They attributed the changes in these parameters to the interface of the electrode and electrolyte. They also examined the effect of $\mathrm{N}_{2} \mathrm{O}$ gas, but no electrode showed a response to it. They discussed a sensing mechanism that involved electron exchange with the metal oxide receptor, however, they declared that it requires further investigation.

Shimizu et al. [23] examined $\mathrm{NO}_{\mathrm{x}}$ sensors consisting of several metal oxides doped with platinum $\left(\mathrm{WO}_{3}, \mathrm{TiO}_{2}\right.$, $\left.\mathrm{WO}_{3} / \mathrm{ZrO}_{2}, \mathrm{WO}_{3} / \mathrm{TiO}_{2}, \mathrm{MoO}_{3} / \mathrm{TiO}_{2}, \mathrm{~V}_{2} \mathrm{O}_{5} / \mathrm{TiO}_{2}\right)$ and equipped with interdigitated $\mathrm{Au}$ electrodes. This sensor type differs from other impedance-based ones in that they substitute platinum-impregnated metal oxide-sensing materials for the more commonly used YSZ. The metal oxides are $n$ type semiconductors $\left(\mathrm{TiO}_{2}\right.$ and $\left.\mathrm{WO}_{3}\right)$ unlike YSZ. As a result, a fundamentally different sensing mechanism is to be expected. The sensor with $\mathrm{Pt}-\mathrm{WO}_{3} / \mathrm{TiO}_{2}$ exhibited a nearly equal response to both $\mathrm{NO}$ and $\mathrm{NO}_{2}$ at $500{ }^{\circ} \mathrm{C}$. They attributed this feature to the $\mathrm{Pt}$ which promotes $\mathrm{NO}_{2}$ decomposition to $\mathrm{NO}$ which is thermodynamically favored at the elevated temperature of these studies. The impedance at $4 \mathrm{~Hz}$ varied nearly linearly with the logarithm of $\mathrm{NO}_{\mathrm{x}}$ $\left(\mathrm{NO}\right.$ or $\mathrm{NO}_{2}$ ) concentration from 10 to $570 \mathrm{ppm}$. The logarithmic relationship may suggest a different mechanism than YSZ sensors, however, YSZ sensors might also exhibit logarithmic behavior over a wide range of analyte gas concentration. The low frequency impedance did not vary much with $\mathrm{O}_{2}$ concentration, which is advantageous in comparison to sensors with YSZ electrolyte because they must be compensated. The authors proposed that the impedance change due to NO addition resulted from enhanced diffusion charge transport at the interface of the metal oxide electrolytes and the electrodes. In specific, NO 
adsorption on the surface of the doped metal oxide causes an enhancement of the diffusion of $\mathrm{H}^{+}$at the interface on account of the interaction of $\mathrm{NO}$ with the acidic $\mathrm{W}-\mathrm{OH}$ site.

\section{Water vapor}

Gutiérez et al. studied changes in the impedance spectra of semiconductor $\mathrm{SnO}_{2}$ due to humidity $\left(\mathrm{H}_{2} \mathrm{O}\right), \mathrm{CO}$, and air. The sensing mechanism results from changes of conductivity with respect dry air due to water vapor. In specific, $\mathrm{OH}^{-}$reacts with $\mathrm{O}_{2}$, thereby decreasing the depletion layer width. This group proposed a Voigt equivalent circuit model similar to the YSZ-based sensors. They did not, however, correlate the changes in impedance to changes in species concentration [6].

Miura et al. [12] did correlate impedance with gaseous species quantity in their original work on $\mathrm{NO}_{\mathrm{x}}$ detection. This work differed from that of Gutiérez et al. on account of the use of YSZ instead of a semiconductor. Nakatou and Miura [35] further applied the impedance-based sensing technique to detect water vapor (humidity) at high temperature. Several different single oxide sensing electrodes were evaluated with stabilized zirconia electrolyte. The maximum sensitivity was found using electrodes of $\operatorname{In}_{2} \mathrm{O}_{3}$ operating at $900{ }^{\circ} \mathrm{C}$. Sensitivity was measured by the change in the magnitude of the impedance, $\Delta \mathrm{Z}$, at $1 \mathrm{~Hz}$. The impedance change was linear with respect to the logarithm of $\mathrm{H}_{2} \mathrm{O}$ concentration (70-30,000 ppm). Response times were measured in single seconds. The sensing mechanism is attributed to a change in impedance. In specific, the resistance of the electrode reaction at the interface of the oxide electrode and YSZ electrolyte decreases with increasing concentration of water vapor in the gas.

\section{Hydrocarbons}

Nakatou and Miura [35] found that the $\mathrm{In}_{2} \mathrm{O}_{3} / \mathrm{YSZ}$ impedancemetric sensor used to detect water vapor also indirectly senses hydrogen and hydrocarbons in dry gas at $900{ }^{\circ} \mathrm{C}$ [36]. They speculated that the sensing mechanism involves the working electrode serving as a catalyst for the oxidation of hydrocarbons that react to form $\mathrm{CO}_{2}$ and $\mathrm{H}_{2} \mathrm{O}$ (water vapor). Whereas the $\mathrm{CO}_{2}$ does not evoke a response, the $\mathrm{In}_{2} \mathrm{O}_{3} / \mathrm{YSZ}$ sensor detects the hydrocarbon indirectly by sensing the water vapor from combustion. Once again, the change in modulus, $\Delta \mathrm{Z}$, was used as the metric for sensitivity. The sensitivity, as measured by the change in impedance due to the analyte gas, is attributed to the change in resistance of the electrode reaction at the interface of the $\mathrm{In}_{2} \mathrm{O}_{3}$ electrode and the YSZ electrolyte.

Nakatou and Miura developed a sensor that can selectively detect propene $\left(\mathrm{C}_{3} \mathrm{H}_{6}\right)$ in a humidified gas stream $\left(1 \mathrm{vol} . \% \mathrm{H}_{2} \mathrm{O}\right)$ at $600{ }^{\circ} \mathrm{C}$ by first oxidizing reducing species and by applying a bias of $+50 \mathrm{mV}$ to the sensing electrode versus the Pt counter electrode [37]. A sensing electrode of $\mathrm{ZnO}$ on $\mathrm{YSZ}$ shows negligible cross-sensitivity to $\mathrm{CH}_{4}$, where sensitivity is measured as the change in modulus upon exposure to a gas. Platinum (1.5 wt.\%) was added to the sensing electrode in order to improve its catalytic activity for oxidation, resulting in the ability to detect propene even in the presence of $\mathrm{CO}, \mathrm{NO}, \mathrm{NO}_{2}, \mathrm{H}_{2}$, $\mathrm{CH}_{4}, \mathrm{CO}_{2}, \mathrm{H}_{2} \mathrm{O}$, and $\mathrm{O}_{2}$. The sensing ability is attributed to the change in the resistance of electrochemical reaction taking place at the interface between the electrode and electrolyte, however, the authors stated that further study is required to understand the exact sensing mechanism.

A follow-up paper by Miura et al. [38] reported that their propene sensor with a $\mathrm{ZnO}$ sensing electrode and YSZ electrolyte detected the specific hydrocarbon at extremely low concentrations ( $0.05-0.8 \mathrm{ppm})$. Sensitivity was defined by the change in modulus; it varied linearly with propene concentration and was only insignificantly affected by $\mathrm{H}_{2} \mathrm{O}, \mathrm{NO}_{2}$, $\mathrm{NO}, \mathrm{H}_{2}, \mathrm{CO}$, and $\mathrm{CH}_{4}$. In this study, an applied potential to the sensing electrode did not greatly affect sensitivity. The effect of propene on impedance is attributed to the change in resistance of the charge transfer reaction that occurs at the interface of the oxide electrode and YSZ electrolyte, which is a refinement of earlier work that suggested the cause was adsorption or electrode reactions for detection of $\mathrm{NO}_{\mathrm{x}}[12$, 18], water vapor [35], and hydrocarbons [36, 37]. The authors cautioned that further examinations on the detailed sensing mechanism were necessary.

In the course of an investigation of $\mathrm{NO}_{\mathrm{x}}$ sensors, Stranzenbach et al. $[28,30]$ examined cross-sensitivity to $\mathrm{CH}_{4}$. Reducing gases caused both ohmic and capacitive changes in the sensor that they associated with the changes in charge carriers in the electrolyte and not with electrode processes. Net oxidizing environments should result in the oxidation of $\mathrm{CH}_{4}$ to $\mathrm{CO}_{2}$, which is not detected by the sensor. No investigation of the effect of water vapor on sensor response took place. The sensors were not calibrated to relate changes in impedance to the species quantity of $\mathrm{CH}_{4}$.

\section{Carbon monoxide}

As discussed above, Gutiérrez et al. [6] noticed changes in the impedance spectra of $\mathrm{SnO}_{2}$ due to several gases including $\mathrm{CO}$, but they did not perform the calibration necessary to make a sensor. They did, however, discuss a possible sensing mechanism. At elevated temperature, $\mathrm{CO}$ reacts with chemisorbed oxygen, which increases the number of carriers, decreases the voltage barriers, and results in increased conductivity.

Stranzenbach et al. $[28,30]$ also looked at the crosssensitivity of a $\mathrm{NO}_{x}$ sensor to $\mathrm{CO}$ in addition to $\mathrm{CH}_{4}$. Since 
both are reducing gases, they drew the same conclusions for $\mathrm{CO}$ as they did for $\mathrm{CH}_{4}$.

$\mathrm{Wu}$ et al. [39] examined an electrochemical $\mathrm{CO}$ sensor with an electrode of Au-doped $\mathrm{Ga}_{2} \mathrm{O}_{3}$ and an electrolyte of YSZ. They chose the $\mathrm{Au}-\mathrm{Ga}_{2} \mathrm{O}_{3}$ material because $\mathrm{CO}$ chemisorbs strongly on it. The change in modulus at $0.1 \mathrm{~Hz}$ was used for sensitivity measurements. An equivalent circuit was proposed: $R_{c}-\left(R_{b} C_{b}\right)-\left(R_{i} Q\right)$ where $R_{c}$ represents contact resistance, the Voigt element $\left(R_{b} C_{b}\right)$ represents the YSZ bulk, and the Cole element $\left(R_{i} Q\right)$ represents the interface between the electrode and the electrolyte. The interpretation of $R_{c}$ is novel because this circuit element is usually associated with the bulk electrolyte whereas here it is the ohmic resistance of the electric connection. The value for $C_{b}$ was on the same order of magnitude as that for bulk YSZ found in a previous study, so the second element was identified as the bulk electrolyte. Neither $R_{c}, R_{b}$, nor $C_{b}$ changes with $\mathrm{CO}$ concentration. Rather the interfacial parameters $R_{i}$ and $Q$ that represent the triple phase boundary respond to changes in $\mathrm{CO}$ concentration, where $Q$ accounts for the non-ideal behavior of the double layer, and $R_{i}$ represents charge transfer. This conclusion agrees with other work [38]. Interfacial impedance depends on the electrolyte and the sensing electrode materials; any change in either could affect the impedance. The authors proposed that $\mathrm{CO}$ gas interacted with the sensor at the TPB in the following way: the alternating voltage induced electrochemical oxidation of $\mathrm{CO}$ thereby introducing charge carriers and changing the kinetics of charge transfer.

\section{Summary}

Impedance-based gas sensors have been surveyed for their materials, equivalent circuit models, and sensing mechanisms. This type of gas sensor is less developed than amperometric or mixed potential types [3]. Impedancemetric sensor designs consist of a simple, single electrochemical cell operating at temperature greater than $500{ }^{\circ} \mathrm{C}$. Typically, the electrolyte consists of YSZ, the sensing electrode of a noble metal or a metal oxide, and the counter electrode of Pt. As a sensing material, dense Pt has been shown to be ineffective for $\mathrm{NO}_{\mathrm{x}}$ detection [27], making it appropriate for a counter electrode material. Symmetric electrode materials are also common. Some sensors consist of semiconducting materials whose electrical properties change in the presence of certain gases. The sensing mechanisms of electrolytic and semiconducting sensors are expected to be different, as would sensors with noble metal vs. metal oxide electrodes. Sensing mechanisms are poorly understood [2]. Further studies with isotopically marked gases are necessary to establish the exact sensing mechanism for the sensors. The rate-limiting step associat- ed with sensing properties depends on sensor morphology, chemistry, and triple-phase boundary [20]. These characteristics differ across sensors, however, it is clear that the influence of the analyte gas is seen at low frequency ( $f \leq$ $100 \mathrm{~Hz}$ ). Usually, the sensing property is attributed to a transport process at the interface of the electrode and the electrolyte.

Typically, a Voigt equivalent circuit model (sometimes with minor variations) is used to replicate impedance behavior over a wide range of frequencies. Most research groups use the change in modulus at a specific frequency (typically $f \leq 10 \mathrm{~Hz}$ ) as the metric for sensitivity. This change in modulus can be linearly correlated to species concentration. Some groups report an equivalent response to $\mathrm{NO}$ and $\mathrm{NO}_{2}$ alike allowing total $\mathrm{NO}_{\mathrm{x}}$ sensing at a specified temperature. It is unclear whether the equivocal sensitivity is due to the detection capability of the sensor or due to the natural thermal equilibrium shift of $\mathrm{NO}_{2}$ to $\mathrm{NO}$. At $T>600^{\circ} \mathrm{C}, \mathrm{NO}_{\mathrm{x}}$ in exhaust gases equilibrates so that the mixture consists primarily of $\mathrm{NO}(>90 \%)$ [2].

Impedancemetric sensors show several promising advantages over conventional sensors. Accurate detection of gaseous species on the single ppm level in high background $\mathrm{O}_{2}$ concentration has been demonstrated $[1,20]$. These sensors do not require an air reference electrode. Some drawbacks exist, however, with impedance-based sensors. Selectivity remains a challenge. The partial pressure of $\mathrm{O}_{2}$ in the sample gas must be known due to cross-sensitivity. In addition, the attendant electronics and signal processing equipment are more complicated than those of conventional sensors. Moreover, the long-term stability of the sensors must be further improved [8], perhaps by heat treatment or by a different fabrication method. In summary, numerous challenges remain to be overcome prior to the commercialization of impedancemetric sensors for gas detection.

Acknowledgments The authors gratefully thank Lawrence Livermore National Laboratory for supporting this work. In particular, the authors acknowledge Dr. Robert Glass and Dr. Leta Y. Woo of Lawrence Livermore National Laboratory for their insights into sensor fabrication and evaluation.

Open Access This article is distributed under the terms of the Creative Commons Attribution Noncommercial License which permits any noncommercial use, distribution, and reproduction in any medium, provided the original author(s) and source are credited.

\section{References}

1. Martin LP, Woo LY, Glass RS (2007) Impedancemetric $\mathrm{NO}_{\mathrm{x}}$ sensing using YSZ electrolyte and $\mathrm{YSZ} / \mathrm{Cr}_{2} \mathrm{O}_{3}$ composite electrodes. J Electrochemical Soc 154(3):J97-J104 
2. Zhuiykov S (2008) Electrochemistry of zirconia gas sensors. CRC Press, New York

3. Fergus JW (2007) Materials for high temperature electrochemical $\mathrm{NO}_{\mathrm{x}}$ gas sensors. Sensor Actuator B Chem 121:652-663

4. Orazem M, Tribollet B (2008) Electrochemical impedance spectroscopy. Wiley, New Jersey

5. Preidel W, von Lucadou I, Lager W, Ruprecht L, Saeger S (1990) Glucose measurements by electrocatalytic sensor in the extracorporeal blood circulation of a sheep. Sensor Actuator B Chem 2:257-263

6. Gutiérrez J, Arés L, Horillo MC, Sayago I, Agapito J, López L (1991) Use of complex impedance spectroscopy in chemical sensor characterization. Sensor Actuator B Chem 4:359-363

7. Liu J, Weppner W (1992) $\theta$-Sensors: a new concept for advanced solid-state ionic gas sensors. Appl Phys A55:250-257

8. Liaw BY, Liu J, Menne A, Weppner W (1992) Kinetic principles for new types of solid state ionic gas sensors. Sol Stat Ion 53-56 (1): $18-23$

9. Steudel E, Weppner W (1996) Electrochemical gas detection based on dynamic measurements. Ionics 2:107-112

10. Oelgeklaus R, Baltruschat H (1997) Detection of hydrocarbons in air by adsorption on Pt-electrodes using continuous impedance measurements. Sensor Actuator B Chem 42:31-37

11. Ernst S, Herber R, Slavcheva E, Vogel I, Baltruschat H (2001) Continuous detection of volatile aromatic, unsaturated or halogenated hydrocarbons in air by adsorption on Pt-electrodes and subsequent oxidative desorption. Electroanalysis 13(14):1191-1197

12. Miura N, Nakatou M, Zhuiykov S (2002) Impedance-based total$\mathrm{NO}_{\mathrm{x}}$ sensor using stabilized zirconia and $\mathrm{ZnCr}_{2} \mathrm{O}_{4}$ sensing electrode operating at high temperature. Electrochem Comm 4:284-287

13. Bard AJ, Faulkner LR (1980) Electrochemical methods fundamentals and applications. Wiley, New York

14. Zhuiykov S, Miura N (2005) Solid-state electrochemical gas sensors for emission control. In: Sorrell CC, Nowotny J, Sugihara $\mathrm{S}$ (eds) Materials for energy conversion devices. Woodhead Publishing, Cambridge, pp 303-335

15. Miura N, Elumalai P, Plashnitsa VV, Ueda T, Wama R, Utiyama M (2009) Solid state gas sensing. In: Comini E, Faglia G, Sberveglieri G (eds) Solid state electrochemical gas sensing. Springer, New York, pp 200-203

16. Bauerle J (1969) Study of solid electrolyte polarization by a complex admittance method. J Phys Chem Solid 30:2657-2670

17. Vestreng V, Ntziachristos L, Semb A, Reis S, Isaksen ISA, Tarrasón L (2009) Evolution of $\mathrm{NO}_{\mathrm{x}}$ emissions in Europe with focus on road transport control measures. Atmos Chem Phys 9:1503-1520

18. Miura N, Nakatou M, Zhuiykov S (2003) Impedancemetric gas sensor based on zirconia solid electrolyte and oxide sensing electrode for detecting total $\mathrm{NO}_{\mathrm{x}}$ at high temperature. Sensor Actuator B Chem 93:221-228

19. Miura N, Koga T, Nakatou M, Elumalai P, Hasei M (2006) Electrochemical $\mathrm{NO}_{\mathrm{x}}$ sensors based on stabilized zirconia: comparison of sensing performances of mixed-potential-type and impedancemetric $\mathrm{NO}_{\mathrm{x}}$ sensors. J Electroceram 17:979-986

20. Martin LP, Woo LY, Glass RS (2007) Impedancemetric technique for $\mathrm{NO}_{\mathrm{x}}$ sensing using a YSZ-based electrochemical cell. Mater Res Soc Symp Proc 972:04-AA12

21. Woo LY, Martin LP, Glass RS, Gorte RJ (2007) Impedance analysis of electrochemical $\mathrm{NO}_{\mathrm{x}}$ sensor using a $\mathrm{Au} / \mathrm{yttria}-$ stabilized zirconia (YSZ)/Au cell. Mater Res Soc Symp Proc 972:02-AA12
22. Woo LY, Martin LP, Glass RS, Gorte RJ (2007) Impedance characterization of a model $\mathrm{Au} / \mathrm{yttria}$-stabilized zirconia/Au electrochemical cell in varying oxygen and $\mathrm{NO}_{\mathrm{x}}$ concentrations. J Electrochem Soc 154(4):J129-J135

23. Shimizu K, Kashiwagi K, Nishiyama H, Kakimoto S, Sugaya S, Yokoi H, Satsuma A (2008) Impedancemetric gas sensor based on Pt and $\mathrm{WO}_{3}$ co-loaded $\mathrm{TiO}_{2}$ and $\mathrm{ZrO}_{2}$ as total $\mathrm{NO}_{\mathrm{x}}$ sensing materials. Sensor Actuator B Chem 130:707-712

24. Ho KY, Miyayama M, Yanagida $\mathrm{H}$ (1997) $\mathrm{NO}_{\mathrm{x}}$ gas responding properties of $\mathrm{Nd}_{2} \mathrm{Cu}_{4-y}$, thick film. Mater Chem Phys 49:7-11

25. Yoon JW, Grilli ML, Di Bartolomeo E, Polini R, Traversa E (2001) The $\mathrm{NO}_{2}$ response of solid electrolyte sensors made using nano-sized $\mathrm{LaFeO}_{3}$ electrodes. Sensor Actuator B Chem 76:483488

26. Murray EP, Novak RF, Kubinski DJ, Soltis RE, Visser JH, Woo LY, Martin LP, Glass RS (2008) Investigating the stability and accuracy of the phase response for $\mathrm{NO}_{\mathrm{x}}$ sensing $5 \%$ mg-modified $\mathrm{LaCrO}_{3}$ electrodes. ECS Trans 6(20):43-62

27. Woo LY, Martin LP, Glass RS, Wang W, Jung S, Gorte RJ, Murray EP, Novak RF, Visser JH (2008) Effect of electrode composition and microstructure on impedancemetric nitric oxide sensors based on YSZ electrolyte. J Electrochem Soc 155(1):J32$\mathrm{J} 40$

28. Stranzenbach M, Gramckow E, Saruhan B (2007) Planar, impedance-metric $\mathrm{NO}_{\mathrm{x}}$-sensor with spinel-type $\mathrm{SE}$ for high temperature applications. Sensor Actuator B Chem 127:224-230

29. Luerßen B, Janek J, Günther S, Kiskinova M, Imbihl R (2002) Microspectroscopy at a moving reduction front in zirconia solid electrolyte. Phys Chem Chem Phys 4:2673-2679

30. Stranzenbach M, Saruhan B (June 10-14, 2007) Planar, impedance-metric $\mathrm{NO}_{\mathrm{x}}$-sensor with $\mathrm{NiO} \mathrm{SE}$ for high temperature applications. Solid-State Sensors Actuators and Microsystems Conference 2007:983-986

31. Stranzenbach M, Saruhan B (2009) Equivalent circuit analysis on $\mathrm{NO}_{\mathrm{x}}$ impedance-metric gas sensors. Sensor Actuator B Chem 137:154-163

32. Rheaume J, Pisano A (May 17-20, 2009) Fractional factorial experimental design applied to the development of an impedancemetric $\mathrm{NO}_{\mathrm{x}}$ sensor. 6th US National Combustion Meeting, Ann Arbor, Michigan 11A2

33. Koba D, Takase S, Shimizu Y (2006) A solid electrolyte impedancemetric $\mathrm{NO}_{\mathrm{x}}$ sensor using oxide receptor. ECS Trans 3 (10): 163-171

34. Shimizu Y, Takase S, Koba D (2008) A NOx sensor based on solid-electrolyte impedance transducer. Adv Mater Res 4750:479-482

35. Nakatou N, Miura N (2004) Impedancemetric sensor based on YSZ and $\operatorname{In}_{2} \mathrm{O}_{3}$ for detection of low concentrations of water vapor at high temperature. Electrochem Comm 6:995-998

36. Nakatou N, Miura N (2005) Detection of combustible hydrogencontaining gases by using impedancemetric zirconia-based watervapor sensor. Sol Stat Ion 176:2411-2415

37. Nakatou N, Miura N (2006) Detection of propene by using newtype impedancemetric zirconia-based sensor attached with oxide sensing-electrode. Sensor Actuator B Chem 120:57-62

38. Wama R, Utiyama M, Plashnitsa VV, Miura N (2007) Highly sensitive impedance-based propene sensor using stabilized zirconia and zinc oxide sensing-electrode. Electrochem Comm 9:2774 2777

39. Wu N, Chen Z, Xu J, Chyu M, Maob SX (2005) Impedance-metric $\mathrm{Pt} / \mathrm{YSZ} / \mathrm{Au}-\mathrm{Ga}_{2} \mathrm{O}_{3}$ sensor. Sensor Actuator B Chem 110:49-53 